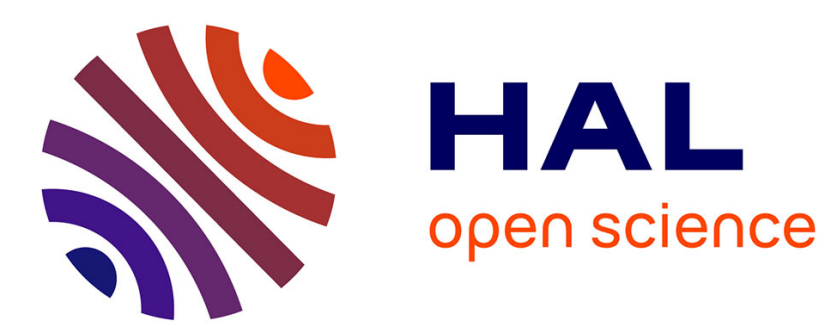

\title{
A Study of Self-Interstitial Atom in W by Means of Low-Temperature Irradiations
}

\author{
H. Tanimoto, H. Mizubayashi, H. Nishimura, S. Okuda
}

\section{To cite this version:}

H. Tanimoto, H. Mizubayashi, H. Nishimura, S. Okuda. A Study of Self-Interstitial Atom in W by Means of Low-Temperature Irradiations. Journal de Physique IV Proceedings, 1996, 06 (C8), pp.C8-285-C8-288. 10.1051/jp4:1996861 . jpa-00254669

\section{HAL Id: jpa-00254669 https://hal.science/jpa-00254669}

Submitted on 1 Jan 1996

HAL is a multi-disciplinary open access archive for the deposit and dissemination of scientific research documents, whether they are published or not. The documents may come from teaching and research institutions in France or abroad, or from public or private research centers.
L'archive ouverte pluridisciplinaire HAL, est destinée au dépôt et à la diffusion de documents scientifiques de niveau recherche, publiés ou non, émanant des établissements d'enseignement et de recherche français ou étrangers, des laboratoires publics ou privés. 


\title{
A Study of Self-Interstitial Atom in W by Means of Low-Temperature Irradiations
}

\author{
H. Tanimoto, H. Mizubayashi, H. Nishimura and S. Okuda* \\ Institute of Materials Science, University of Tsukuba, Tsukuba, Ibaraki 305, Japan \\ * Faculty of Engineering, Ibaraki University, Hitachi, Ibaraki 316, Japan
}

\begin{abstract}
To clarify the migration behavior of self-interstitial atoms (SIA's) in W, we have performed anelasticity measurements of $\mathrm{W}$ after $2 \mathrm{MeV}$ electron irradiation at $5 \mathrm{~K}$ and after $20 \mathrm{MeV}$ proton irradiation at $1.5 \mathrm{~K}$. Dislocation pinning results observed during irradiation clearly show that free SIA's in W migrate below $1.5 \mathrm{~K}$. Warm-up measurements after irradiation reveal higher temperature pinnings which all show no dose shift as reported for substages of the stage I in the electrical resistivity measurements after low-temperature electron irradiation, suggesting that these pinnings are due to SIA's released from traps. After the present results, one can say that the migration temperature of free SIA's in the refractory BCC metals is, in general. very low as below 1.5 $\mathrm{K}$ in $\mathrm{W}$ and below $6 \mathrm{~K}$ in $\mathrm{Nb}$ and Ta with the exception of about $40 \mathrm{~K}$ in Mo.
\end{abstract}

\section{INTRODUCTION}

Recent re-examination of Mo after low-temperature irradiation provides the answer to the controversy on the migration behavior of self-interstitial atoms (SIA's) in the BCC metals [1,2]. In review, <110>dumbbell SIA's can rotate at about $41 \mathrm{~K}$ giving a relaxation peak and undergo three-dimensional migration at about $40 \mathrm{~K}$. In the as-irradiated state, the fractional concentration of the $\langle 110\rangle$-SIA's in the total concentration of induced SIA's decreases with increasing dose due to a strong interaction between irradiation induced defects and complementally, SIA's of the another type which reveal no relaxation peak and undergo free migration at about $43 \mathrm{~K}$ come to share the major part at higher doses. On the other hand, the migration behavior of SIA's in W is still an open question: In the anelasticity measurements of $\mathrm{W}$ after low-temperature fast-neutron irradiation [3], the authors claimed that <110>-dumbbell SIA's can rotate at about $8 \mathrm{~K}$ giving a relaxation peak and undergo three-dimensional migration at about $16 \mathrm{~K}$ and $<110>$-di-intersititials reveal the relaxation peak at about $28 \mathrm{~K}$ showing recovery during peak measurements. On the other hand, in the electrical resistivity measurements after low-temperature electron irradiation $[4,5]$, no dose shift is observed for the well-defined substages at 11,17 (the most predominant), $30.5,38$ and $43 \mathrm{~K}$ except for a quite small substage at $25-29 \mathrm{~K}$, where the substage at 25 $29 \mathrm{~K}$ is claimed to reflect free migration of SIA's, the substages at $11,17,30.5$ and $38 \mathrm{~K}$ are attributed to the close-pair recombination and the substage at $43 \mathrm{~K}$ to some cluster rearrangement, respectively. To clarify this issue, we carried out the dislocation pinning measurements on $\mathrm{W}$ after low-temperature proton irradiation [6] and here after low-temperature electron irradiation.

\section{EXPERIMENTAL PROCEDURES}

Reed-shaped specimens were prepared from the commercially distributed W single crystal rods with the residual resistivity ratio being higher than 8000 , where strips cut out from the single crystal rods were polished into the reed shape of $0.15 \times 3 \times 15 \mathrm{~mm}^{3}$ with one end left thick for clamping. After chemical etching to remove the surface layer by about $10 \mu \mathrm{m}$, the specimens were annealed at $2473 \mathrm{~K}$ for $2 \mathrm{~h}$ in a vacuum of $10^{-7} \mathrm{~Pa}$. Low-temperature irradiation was performed at $5 \mathrm{~K}$ by using $2 \mathrm{MeV}$ electrons from the single-end accelerator at the Japan Atomic Energy Research Institute, Takasaki. The Frenkel defect concentration $\left(C_{\mathrm{FP}}\right)$ is estimated from the dose and the reported data of $1 \mathrm{ppm} C_{\mathrm{FP}}$ per $2.25 \times 10^{15} \mathrm{e} / \mathrm{cm}^{2}$ [7]. The resonant frequency $(f)$ of the flexural vibration of the reed and the internal friction $\left(Q^{-1}\right)$ were 
measured every $30 \mathrm{~s}$ during irradiation and the warm-up and cool-down runs after irradiation.

\section{RESULTS AND DISCUSSIONS}

Figure 1 shows $f$ and $Q^{-1}$ observed for a $\mathrm{W}_{<100>}$ specimen $(<100\rangle$ denotes the crystallographic direction along the longest axis of the reed used), where irradiation was carried out at $5 \mathrm{~K}$ with a total dose corresponding to $C_{\mathrm{FP}}=0.79 \mathrm{ppm}$. As indicated by the vertical arrows, during irradiation both $f$ and $Q^{-1}$ showed strong changes reflecting dislocation pinning. During warm-up after irradiation, the further dislocation pinnings proceeded between 20 and $50 \mathrm{~K}$. The second irradiation with the comparable dose gave raise the further small dislocation pinning suggesting the saturation of pinning effects (not shown in Fig.1 because of much the small changes in $f$ and $Q^{-1}$ ).

An increase in $f$ and a decrease in $Q^{-1}$ due to dislocation pinning can be explained by the following equations [8],

$$
\begin{aligned}
& \left(f-f_{\mathrm{s}}\right) / f_{\mathrm{S}}=\alpha(1+n)^{-2} \\
& Q^{-1}=\beta(1+n)^{-4}
\end{aligned}
$$

where $f_{\mathrm{s}}$ is $f$ observed after the saturation of pinning, $f_{\mathrm{s}}=337.211 \mathrm{~Hz}$ in Fig. $1, n$ the mean number of pinners arrived on dislocation loops, and $\alpha$ and $\beta$ are proportional constants. Figure 2 shows the results of application of Equation (1) to the changes in $f$ at $5 \mathrm{~K}$ observed for the first irradiation as shown in Fig. 1 and for the second irradiation, where a relative change in $n$ during irradiation and that after subsequent warm-up are plotted. When the dislocation pinning observed during irradiation is caused by SIA's arrived on dislocations via free migration, the following rate equation for the concentration of SIA's $\left(C_{i}\right)$ can be expected in the specimen under irradiation,

$$
\mathrm{d} C_{\mathrm{i}} / \mathrm{d} t=\gamma \Phi-R C_{\mathrm{i}} C_{\mathrm{v}}-K C_{\mathbf{i}}
$$

where $\gamma \Phi$ denotes the formation rate of SIA's under the dose rate $\Phi, R C_{\mathrm{i}} C_{\mathrm{v}}$ the trapping by vacancies and $K C_{\mathrm{i}}$ the trapping by dislocations. In Equation (3), we neglect the recombination of SIA's and vacancies during irradiation after the electrical resistivity results $[4,5]$ and also the reaction between SIA's giving SIA-clusters because of the low $C_{\mathrm{FP}}$ used here. Under further assumptions of $C_{\mathrm{V}}=\Phi t$ and $\mathrm{d} C_{\mathrm{i}} / \mathrm{d} t=0$, Equation (3) may give the following relationship between $n$ and $\Phi t$,

$$
n=(\chi K / R) \ln (R \Phi t / K+1)
$$

where $\chi$ is a proportional constant. In Fig. 2, the result of application of Equation (4) to the data observed during the first irradiation is shown by

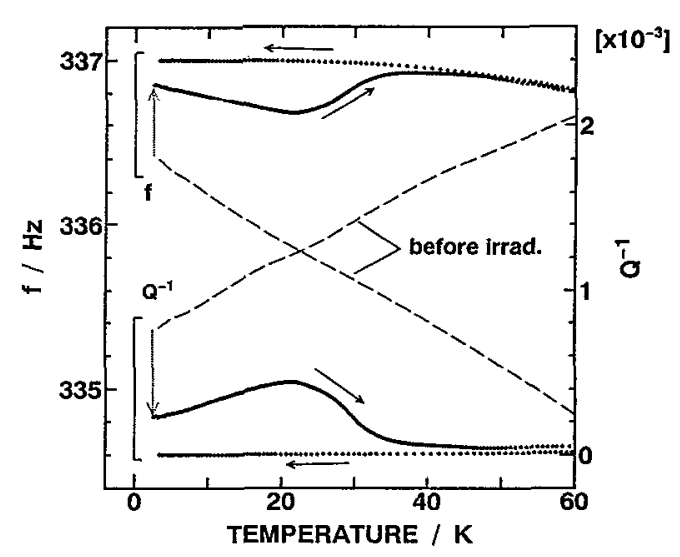

Figure 1. Resonant frequency $(f)$ and internal friction $\left(Q^{-1}\right)$ observed for a $W_{<100}$ specimen. Irradiation was carried out at $5 \mathrm{~K}$ with the induced Frenkel defect concentration $\left(C_{\mathrm{FP}}\right)$ of $0.79 \mathrm{ppm}$. The dashed curves denote the data observed before irradiation, the dotted vertical arrows the changes observed during irradiation at $5 \mathrm{~K}$ and symbols the data observed during warm-up and cool-down after irradiation.

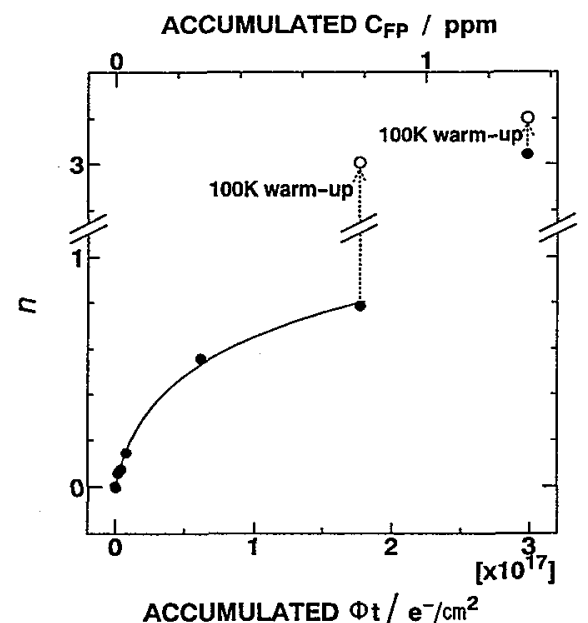

Figure 2. The number density (n) of pinners arrived on dislocations which is estimated from the changes in $f$ at $5 \mathrm{~K}$ shown in Fig. 1 for the first irradiation and for the second irradiation. See Equation (4) for the curve fitted to the data during the first irradiation. 
the solid curve where good agreement can be seen. The $Q^{-1}$ data is also well explained by Equation (4) but not shown here. These results suggest that SIA's in W undergo free migration below $5 \mathrm{~K}$. Further the combination of the present results and the dislocation pinning measurements after 20 $\mathrm{MeV}$ proton irradiation at $1.5 \mathrm{~K} \mathrm{[6]} \mathrm{suggests} \mathrm{that}$ SIA's in $\mathrm{W}$ are mobile at $1.5 \mathrm{~K}$, indicating that the free migration temperature of SIA's in W is lower than $1.5 \mathrm{~K}$. It is noted that for higher dose measurements, the $8 \mathrm{~K}$ relaxation peak found after fast neutron irradiation [3] was observed after 20 $\mathrm{MeV}$ proton irradiation [6] but not after $2 \mathrm{MeV}$ electron irradiation (see Fig.3), suggesting that the $8 \mathrm{~K}$ relaxation peak is due to SIA's trapped by cascade damages.

To pursue the dislocation pinnings at the substages found in the resistivity measurements, very low dose measurements were carried out to avoid the saturation of dislocation pinnings. Figure 4 shows examples of repetition of irradiation with increasing dose which were made using another virgin $\mathrm{W}_{<100>}$ specimen. In Fig. 4 , the temperature derivatives of $f\left(\mathrm{~d}\left(f / f_{0}\right) / \mathrm{d} T\right)$ observed during warm-up after irradiation are plotted against measurement temperatures, where a dislocation pinning after irradiation can be revealed as a peak ( $f_{0}$ denotes $f$ at $5 \mathrm{~K}$ before irradiation). The 38 and $45 \mathrm{~K}$ pinnings are predominant and the minor pinnings are observed at around 11,20 and $30 \mathrm{~K}$. The close investigation of the dislocation pinnings shows no dose shift for all the pinnings, suggesting that SIA's arrived on dislocations at these pinning temperatures are SIA's released from some traps. This view is compatible with the view reported for the substages at $11,17,30.5,38$ and $43 \mathrm{~K}$ found in the electrical resistivity measurements after electron irradiation [4,5]. For higher dose measurements, the relaxation peak due to the rotational motion of $\langle 110\rangle$-defects is observed at about $28 \mathrm{~K}$ after $2 \mathrm{MeV}$ electron irradiation (Fig. 3) as well as after fast neutron irradiation [3] or $20 \mathrm{MeV}$ proton irradiation [6]. The $28 \mathrm{~K}$ peak shows a recovery during the peak measurements. In contrast, in the dislocation pinning measurements at very low dose as shown in Fig. 4 , no pronounced dislocation pinning can be seen at around $28 \mathrm{~K}$. Thus we surmise that the $<110>$-defects responsible for the $28 \mathrm{~K}$ peak are SIA's trapped by vacancies.

In conclusion, the free migration temperature of SIA's in $\mathrm{W}$ is below $1.5 \mathrm{~K}$. For other refractory $\mathrm{BCC}$ metals, the free migration temperature of SIA's is reported to be below $6 \mathrm{~K}$ in $\mathrm{Nb}$ and $\mathrm{Ta}$ and about $40 \mathrm{~K}$ in Mo. That is, the migration temperature of SIA's is very low for all the refractory $\mathrm{BCC}$ metals except for Mo. The detailed results and discussion will be given elsewhere.

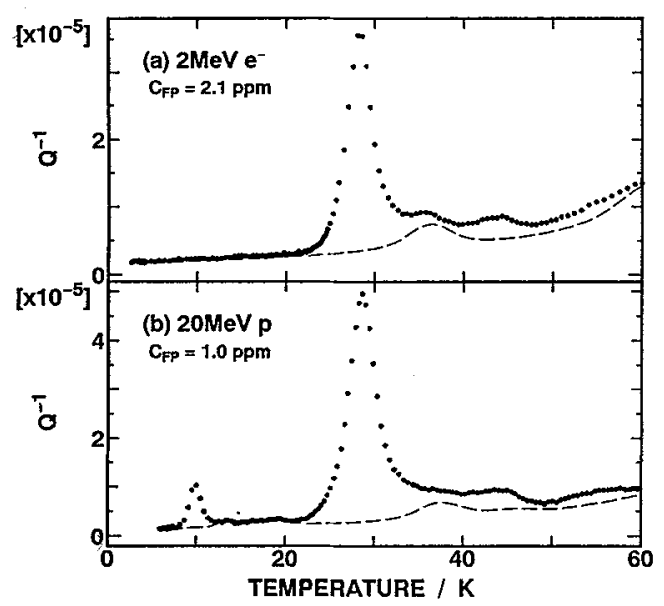

Figure 3, $Q^{-1}$ spectra observed during warmup (a) after $2 \mathrm{MeV}$ electron irradiation at $5 \mathrm{~K}$ with $C_{\mathrm{FP}}=2.1 \mathrm{ppm}$ and (b) after $20 \mathrm{MeV}$ proton irradiation at $1.5 \mathrm{~K}$ with $C_{\mathrm{FP}}=1.0 \mathrm{ppm}$. The dashed lines show the data observed during the following cool-down runs.

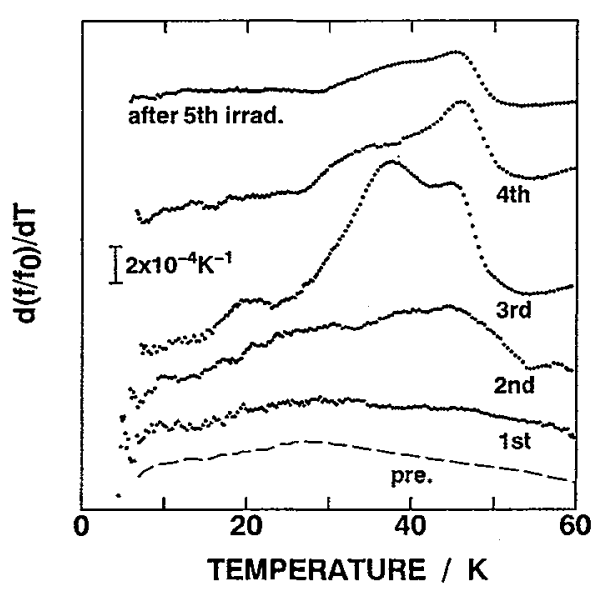

Figure 4. Change in the normalized temperature derivative of $f\left(\mathrm{~d}\left(f / f_{0}\right) / \mathrm{d} T\right)$, observed for another virgin $W_{<100}$ specimen during warm-up after $2 \mathrm{MeV}$ e irradiation at $5 \mathrm{~K}(f$ is $f$ observed before irradiation at $5 \mathrm{~K}$ and the dashed line "pre." denotes the data observed before irradiation). The irradiation was repeated with increasing dose where $C_{\mathrm{FP}}$ was $3 \times 10^{-5}, 2.5 \times 10^{-4}, 8.3 \times 10^{-3}, 0.086$ and 0.78 ppm for the 1st, 2nd, 3rd, 4th and 5th irradiations, respectively. 


\section{Acknowledgments}

Authors indebted to Dr. A. Iwase, the Japan Atomic Energy Research Institute, for the cooperation at the electron irradiation experiments and variable discussion. This study was financially supported by the Sumitomo Foundation.

\section{References}

1. Tanimoto H., Mizubayashi H., Masuda R., Okuda S., Iwata T., Takeshita H. and Naramoto H., Phys. Status Solidi A, 132(1992)353-360.

2. Tanimoto $\mathrm{H}$., Mizubayashi H., Teramae $\mathrm{N}$. and Okuda S., J. Alloys and Compounds, 211/212(1994)54-57, 136-139.

3. Okuda S. and Mizubayashi H., Phys. Rev. Lett., 34(1975)815-817; Phys. Rev., B13(1976)42074216.

4. Dausinger V.F., Phil. Mag., 37(1978)819-836.

5. Schultz H., Mat. Sci. Forum, 15/18(1978)727-732.

6. Tanimoto H., Mizubayashi H. and Okuda S., "Proc. 1st Int. Conf. on Ultra High Purity Base Metals (UHPM-94)", Abiko K. et al. Eds., Kitakyushu-city(Japan) 24-27 May 1994, pp.472-477.

7. Jung P., "Landolt-Börnstein New Series Group III: Crystal and Solid State Physics Vol.25" Ullmaier H. Ed., (Springer-Verlag, Berlin, 1991), p.51.

8. Keefer D., Robinson J.C. and Sosin A., Acta. Metall., 13(1965)1135-1152. 